\title{
The Stripping Foil Test Stand in the Linac4 Transfer Line
}

W. Weterings, C. Bracco, R. Noulibos, Y. Sillanoli, P. van Trappen

CERN, European Organization for Nuclear Research, CH-1211 Geneva 23, Switzerland

\begin{abstract}
The $160 \mathrm{MeV} \mathrm{H}$ - beam from the Linac4 linear accelerator at CERN will be injected into the Proton Synchrotron Booster with a new $\mathrm{H}-$ charge-exchange injection system. It will include a stripping foil, to convert $\mathrm{H}-$ into protons by stripping off the electrons. To gain experience with these very fragile foils, prior to the installation in the PSB, and test different foil materials and thicknesses, lifetimes of the foils, the foil changing mechanism and interlocking functions, a stripping foil test stand will be installed in the Linac4 transfer line in 2015. This paper describes the mechanical design of the system and discusses the test possibilities and parameters.
\end{abstract}

Keywords: charge stripping, $\mathrm{H}^{-}$injection, charge-exchange, stripping foil, test stand, solid stripper

\section{Introduction}

CERN, the European Organization for Nuclear Research, has put in place an ambitious improvement programme to make the injector chain of the Large Hadron Collider (LHC) capable of supplying the high intensity and high brightness beams requested by the High-Luminosity LHC (HL-LHC) project. This LHC Injectors Upgrade (LIU) project comprises a new Linac, so-called Linac4, as well as major upgrades and renovations of the Proton Synchrotron Booster (PSB), the Proton Synchrotron (PS) and the Super Proton Synchrotron (SPS) [1,2]. Linac4 (L4) is an $\mathrm{H}^{-}$linear accelerator, intended to replace Linac2 as injector to the PSB, delivering a beam at $160 \mathrm{MeV}$ energy [3]. The PSB consists of 4 superposed synchrotron rings and the $160 \mathrm{MeV}$ beam from the L4 transfer line will be distributed to the four rings by a vertical bending magnet (DVT30), a system of 5 kicker magnets (DIS), a vertical bend (DVT40) and 3 septum magnets (SMV) [4]. The beam will subsequently be injected horizontally into the PSB by means of a $\mathrm{H}^{-}$charge exchange injection system, one for each ring, through a carbon foil converting $\sim 98 \%$ of the beam to protons. Partially stripped $\mathrm{H}^{0}$ and $\sim 1 \% \mathrm{H}^{-}$missing the foil will be 
directed to an internal $\mathrm{H}^{0} / \mathrm{H}^{-}$dump [5].

The local orbit of the PSB beam is displaced by $\sim 81 \mathrm{~mm}$, using two independent closed orbit bump systems, to meet the incoming beam. The first, called the injection bump, is made by a set of 4 pulsed dipole magnets (BSW) located in the injection straight section, and displaces the beam by a constant $46 \mathrm{~mm}$ during the injection process. A series of 4 horizontal kickers (KSW), outside the injection region, will produce a $35 \mathrm{~mm}$ closed orbit bump, with falling amplitude during the injection, to accomplish transverse phase space painting to the required emittance [6]. A schematic representation of the PSB injection region and the $\mathrm{H}^{-}$charge exchange principle is given in Fig. 1. Beam commissioning of L4 will take place in steps of increasing energy, to reach the final $160 \mathrm{MeV}$ in 2015 . An extended beam measurement phase, including a test stand of the foil handling and exchange mechanism for the PSB, and a year-long test run to assess and improve L4 reliability will take place in 2016, prior to the connection of Linac4 to the PSB that will take place during the next long LHC shut-down [7].

\section{Foil Handling and Exchange Mechanism}

The foil handling and exchange mechanism, illustrated in Fig. 2, is based on the FS6 foil changer from NEC, Wisconsin USA, and the unit for the L4 test stand is identical to the mechanism intended to be installed in the PSB. It consists of a rotating stainless steel belt, to which a maximum of 6 foil holders can be attached by use of quick disconnect sliders. The support edges of the stainless steel foil holder are kept outside the beam acceptance of the PSB, in order not to intercept the circulating beam. The design and dimensions of the foil holder are shown in Fig.

3. Due to the limited space between the BSW2 and BSW3 magnets, the stripping foil cannot be at the exact theoretical stripping point location, as shown in Fig. 1, but will be positioned with an offset of $\sim 30 \mathrm{~mm}$ longitudinal, downstream of the straight section centre.

The rotation of the belt is done by an outside vacuum stepping motor attached by a magnetic coupling to the driving pulley of the belt, thus having no rotating vacuum seals to assure ultra-high vacuum (UHV) compatibility. The exchange mechanism allows each foil to move into the nominal beam position with a precision of $\pm 0.1 \mathrm{~mm}$ from which a foil movement in the horizontal plane of $\pm 2 \mathrm{~mm}$ is possible in order to adjust the injection and cover the movement for setting up from a retracted position to the nominal position. Since the foil will cover the total 
vertical beam acceptance no vertical adjustment is necessary.

The stepping motor has a step angle of $1.8^{\circ}$ and the driving pulley has a diameter of $24 \mathrm{~mm}$, giving a resolution of $\approx 0.38 \mathrm{~mm} / \mathrm{step}$. In order to meet the required specification, a gearbox with a 10:1 ratio is used giving a final resolution of $\approx 0.038 \mathrm{~mm} / \mathrm{step}$. The stripping foils are fragile and can easily be damaged by vibration and for this reason a micro-stepping driver will be used to have a smooth foil movement. The foil IN or OUT position is controlled by UHV compatible micro-switches and a purpose-built U-shaped potentiometer, from Hoffmann + Krippner GmbH, made of conductive ink on Kapton®, is used to deduce the precise foil position.

In order to avoid foil damage, due to differential pressure and to optimise intervention times, it will be possible to isolate the foil exchange system from the overall L4 vacuum system.

\section{Stripping Foil Specification}

The material choice and thickness of the foil is driven by the stripping efficiency, beam loss through nuclear scattering, emittance blow-up of the circulating beam and temperature rise of the foil. For thermal stability, high sublimation temperature, radiation resistance and mechanical reasons the stripping foil material will be carbon, either in amorphous or diamond form.

Goddard et al. [8] specified that the foil should be $<250 \mu \mathrm{g} / \mathrm{cm}^{2}$ in thickness to keep the emittance increase below $0.1 \pi \cdot \mu \mathrm{rad}$, for the $\sim 2 \pi \cdot \mu \mathrm{rad}$ requirements of the LHC beam at injection. In order to keep the uncontrolled beam loss below the $10^{-4}$ level a foil thickness $<200 \mu \mathrm{g} / \mathrm{cm}^{2}$ is required. However, to ensure a theoretical stripping efficiency $>99 \%$ the thickness should be $>150 \mu \mathrm{g} / \mathrm{cm}^{2}$. Since the benefits of a thicker foil outweigh the disadvantages of extra foil heating, losses and emittance blow-up, a foil thickness of $200 \mu \mathrm{g} / \mathrm{cm}^{2}(\sim 1 \mu \mathrm{m})$ has been specified. Simulations have shown that the highest foil temperatures are obtained for a high intensity beam, where emittances around 8 and $6 \pi \cdot \mu \mathrm{rad}$ are assumed in the horizontal and vertical planes, respectively. The temperature rise for a single injection of $1.3 \times 10^{13} \mathrm{p}^{+}$is about $280 \mathrm{~K}$. The effect of multiple injections at the PSB repetition rate of $0.833 \mathrm{~Hz}$ was investigated [8,9], assuming only black-body radiation cooling. An equilibrium peak temperature of $650 \mathrm{~K}$ is reached after a few cycles. Thermal foil damage is therefore unlikely to be a foil lifetime or performance issue. The foil lifetime is expected to be dominated by purely mechanical effects or by accidents, 
such as shocks or being moved into the circulating beam.

To minimize the losses occurring from beam missing the foil, the foil size needs to be large enough to fully cover the incoming $\mathrm{H}^{-}$beam. Nevertheless, a too large foil will result in larger numbers of foil hits per proton during injection and subsequent increases in beam loss, emittance and foil temperature. The optimum [9] width of the foil is $21 \mathrm{~mm}$ for injection with zero dispersion at the end of the transfer line. To accommodate for other optics parameters, the overall design remains compatible for foils with a width up to $32 \mathrm{~mm}$.

\section{Instrumentation}

The test stand will be equipped with an optical beam observation system (BTV), including a $1 \mathrm{~mm}$ thick Chromox $\left(\mathrm{Al}_{2} \mathrm{O}_{3}\right.$ doped with $\left.\mathrm{CrO}_{2}\right)$ scintillating screen, engraved with calibration marks, which is remotely controllable to be normally outside the beam path and only inserted when needed for beam measurements, and a radiation-hard camera allowing either the beam position or the integrity of the stripping foil to be monitored. The system, as shown in Fig. 2, has a position accuracy of $\pm 0.2 \mathrm{~mm}$ and allows quantitative beam measurements over a large range of beam intensities; a system of remotely controlled optical filters is included to adapt the light intensity to the camera.

In order to observe the screen and the stripping foil with the same camera they are installed very close $(\sim 5 \mathrm{~mm})$ one to another in order to be inside the field depth of the focusing lens making the use of a single, fixed, optical system possible. A mirror is positioned below the beam and reflects the images of the screen, or of the stripping foil, towards an observation viewport above the beam line, which is made of fused silica to avoid the browning that occurs for normal glass in radiation environments. The insertion and extraction of the screen is performed using a linear electrical actuator which rotates the screen around a pivot point. Due to the vicinity of the screen to the fragile stripping foil, all vibrations should be avoided and for this reason an electrical actuator was chosen rather than a pneumatic system.

A stripping foil current measurement will be made by means of taking the electrical signal from the foil holder. A change in signal will give an indication of degrading stripping efficiency or the lifetime of the foils; a signal loss would indicate a broken foil. Furthermore, the stripping efficiency will also be determined, only up to an accuracy 
of a few $\%$, by measuring the decrease in current between two cross-calibrated Beam Current Transformers (BCT) installed upstream and downstream of the stripping foil test stand.

An attempt will be made to estimate of the emittance growth of the beam through the stripping foil with the three monitor method using the Secondary Electron Monitor (SEM) profile grids in L4 beam line.

\section{Layout}

The stripping foil unit will be installed between the L4 PI-Mode Structure (PIMS) and the main dump, as shown in

Fig. 4, so that tests at $160 \mathrm{MeV}$ will be possible. The lattice consists of one defocussing quadrupole (QD) and one focussing quadrupole $(\mathrm{QF})$, one dipole which either bends the beam towards the PSB or lets the beam go towards the main dump, and three correctors. The test unit will be placed between the two quadrupoles; the upstream one (L4T.MQD.0110) will be used to vary the beam size at the foil. V. Dimov's studies showed that, by changing the magnetic field gradient from $2.5 \mathrm{~T} / \mathrm{m}$ up to $9 \mathrm{~T} / \mathrm{m}$, the horizontal beam size (90\%) can be varied from $2.5 \mathrm{~mm}$ to $3.7 \mathrm{~mm}$ respectively and the vertical beam size from $7.4 \mathrm{~mm}$ to $4.2 \mathrm{~mm}$. Moreover, the beam can be transported to the main dump without any losses, provided that the downstream QF (L4T. MQF.0210) is switched off. Furthermore, this part of the line is fully equipped with beam diagnostics. In particular two BCTs, one upstream and one downstream of the foil, and four SEM profile Grids and one Beam Loss Monitor (BLM) are located after the test unit.

\section{Test Possibilities and Beam Parameters}

Stripping efficiency, losses and emittance growth can be measured for different foil thickness (i.e. 150 to 300 $\mu \mathrm{g} / \mathrm{cm}^{2}$ ) and beam conditions. The stripping efficiency as a function of the carbon foil thickness was estimated by scaling the charge exchange cross-sections measured at $200 \mathrm{MeV}$ to $160 \mathrm{MeV}$ [8]. The current before and after the foil can be measured with the BCT, cross calibrated with the electrical signal taken from the foil holder, to evaluate the real stripping efficiency and detect possible foil degradation. Only less than $1 \% \mathrm{H}^{-}$is expected so that the effect on the current measurements can be neglected. During these measurements the SEM Grids have to be out of the beam line to avoid polluting the current signal with $\mathrm{p}^{+}$produced at the wires. The BCTs have a resolution of 0.1 
$\mathrm{mA}$ and an accurate relative calibration between the two monitors is required. The nominal L4 current is $40 \mathrm{~mA}$; a difference of $0.4 \mathrm{~mA}$ between upstream and downstream of the $150 \mu \mathrm{g} / \mathrm{cm}^{2}$ stripping foil is calculated while for thicknesses larger than $200 \mu \mathrm{g} / \mathrm{cm}^{2}$ no measurable difference is expected. Losses at the level of few $10^{9}$ protons (for the nominal intensity of $10^{14} \mathrm{H}^{-}$from L4) are expected. The minimum quadrupole field (2.5 T/m) should be used for stripping efficiency measurements to minimize the horizontal beam size and ensure that the foil intercepts the full beam.

Optics conditions, which are close to the nominal L4 values at the PSB injection point, can be obtained by powering the quadrupole at $9 \mathrm{~T} / \mathrm{m}$. In this case an emittance blowup of 2-3\%, both in the horizontal and vertical plane, is expected for a $200 \mu \mathrm{g} / \mathrm{cm}^{2}$ foil and $4-5 \%$ for $300 \mu \mathrm{g} / \mathrm{cm}^{2}$. Since all the profile monitors are downstream of the foil, measurements have to be repeated with and without the stripping foil in the beam line. Nevertheless such emittance blow-ups are hardly measurable. A blow-up larger than $10 \%$ can be obtained only in the vertical plane with $2.5 \mathrm{~T} / \mathrm{m}$ at the QD.

The PSB injection worst failure scenario, a DIS malfunction, can be simulated by hitting the foil with a $400 \mu \mathrm{s}$ pulse and the minimum beam size at the foil. During this measurement the SEM Grids have to be out of the beam line since their operation is limited to $40 \mathrm{~mA}$ and $100 \mu$ s pulses. Possible effects on the stripping efficiency after such an event can be evaluated with the BCTs.

The test stand will also give the opportunity to conduct many mechanical tests, e.g. the lifetime of the foil and foil holders since no beam induced damage is expected, the peak temperature of the foil is well below the graphite sublimation temperature. Measurement of the foil temperature is currently not foreseen in the set-up. During the test program mechanical cycles and movement of the foil, with and without beam, are foreseen to test the detection of foil breaking (loss of foil current signal) and the rigidity of different types of foils. The BTV system will be tested including the selection of the correct filters and gains for the beam measurements over a large range of beam intensities. For safe operation, it shall not be possible to move the screen into the beam while the foil is moving, nor move the foil when the screen is in position. Only screen movement when the foil has the IN or OUT of beam position shall be possible and these situations shall all be tested. Many of these tests can be performed in parallel to L4 beam tests. 


\section{Conclusion}

A stripping foil test stand will be installed in the Linac4 transfer line between the PI-Mode Structure and the main dump. This will allow many different studies and tests of the foil handling and exchange mechanism, controls, interlocks and instrumentation. It will also allow a rough measurement, at the \% level, of the stripping efficiency for different foils by using two Beam Current transformers as well as from an electrical signal from the foil holder. An attempt to do a rough estimate of the emittance growth of the beam through the stripping foil will be done. The operation of the test stand will be in parallel with Linac4 operation and is anticipated to start autumn 2015.

\section{References}

[1] Damerau H, Garoby R, Gilardoni S.S, Goddard B, Hanke K, Lombardi A.M, Meddahi M, Mikulec B, Shaposhnikova E.N, Vretenar M (2012) Upgrade Plans for the LHC Injector Complex. Conf. Proc. IPAC12, TUXA02:1010-1014;

[2] Damerau H, Deleu A, Funken A, Garoby R, Gilardoni S.S, Gilbert N, Goddard B, Hanke K, Holzer E.B, Lombardi A.M, Manglunki D, Meddahi M, Mikulec B, Shaposhnikova E.N, Vretenar M (2014) Status of the LIU Project at CERN. Conf. Proc. IPAC14, THPME070:3397-3399;

[3] Gerigk F, Vretenar M et al., (2006) Linac4 Technical Design Report, CERN-AB-2006-084

[4] Balhan B, Benedetto E, Borburgh J, Bracco C, Carli C, Goddard B, Hanke K, Mikulec B, Newborough A, Noulibos R, Tan J, Weterings W.J.M (2012) Status of the $160 \mathrm{MeV} \mathrm{H}^{-}$Injection into the CERN PSB. Conf. Proc. IPAC12, TUPPR091:2041-2043;

[5] Delonca M, Maglioni C, Patapenka A.A, Sarrió Martínez A (2012) Internal $\mathrm{H}^{0} / \mathrm{H}^{-}$Dump for the Proton Synchrotron Booster Injection at CERN. Conf. Proc. IPAC12, TUPPR054:1942-1944;

[6] Bracco C, Carli C, Fowler T, Goddard B, Gräwer G, Lallement J.-B, Martini M, Scholz M, Weterings W.J.M (2011) Studies on Transverse Painting for $\mathrm{H}^{-}$Injection into the PSB. Conf. Proc. IPAC11, THPS052:3544-3546;

[7] Vretenar M et al. (2014) Status and Plans for Linac4 Installation and Commissioning. Conf. Proc. IPAC14, THPME048:3332-3334;

[8] Aiba A, Bracco C, Carli C, Goddard B, Meddahi M, Weterings W.J.M (2010) Stripping Foil Issues for $\mathrm{H}^{-}$ Injection into the CERN PSB at $160 \mathrm{MeV}$. Conf. Proc. IPAC10, THPEB030:3951-3953;

[9] Aiba M, Carli C, Goddard B, Weterings W.J.M (2009) Stripping foils for the PSB H- injection system. CERN-sLHC-Project-Note-0005

\section{Figures}

Fig. 1 Configuration of the PSB injection region with 380mm long BSW magnets $(316 \mathrm{~mm}$ magnetic length, 
$126 \mathrm{mTm}$ magnetic field, 66mrad deflection) showing the $\mathrm{H}^{-}$charge exchange principle of the injected and circulating beam.

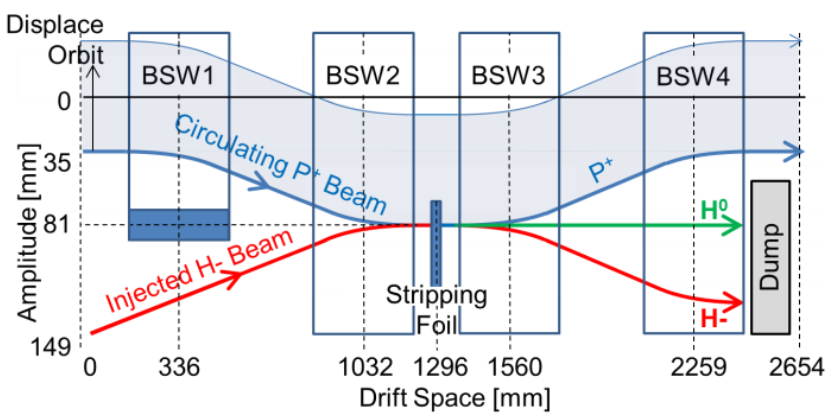

Fig. 2 Partial cross-section of the UHV stripping foil unit design showing the foil exchange mechanism (a), stepping motor with magnetic coupling (b), the beam observation system (BTV) with Chromox screen in retracted position (c), the BTV motorisation (d), radiation hard camera (e) with mirror and optical filters unit (f) and the mirror positioned below the beam $(\mathrm{g})$. The arrow indicates the beam direction.

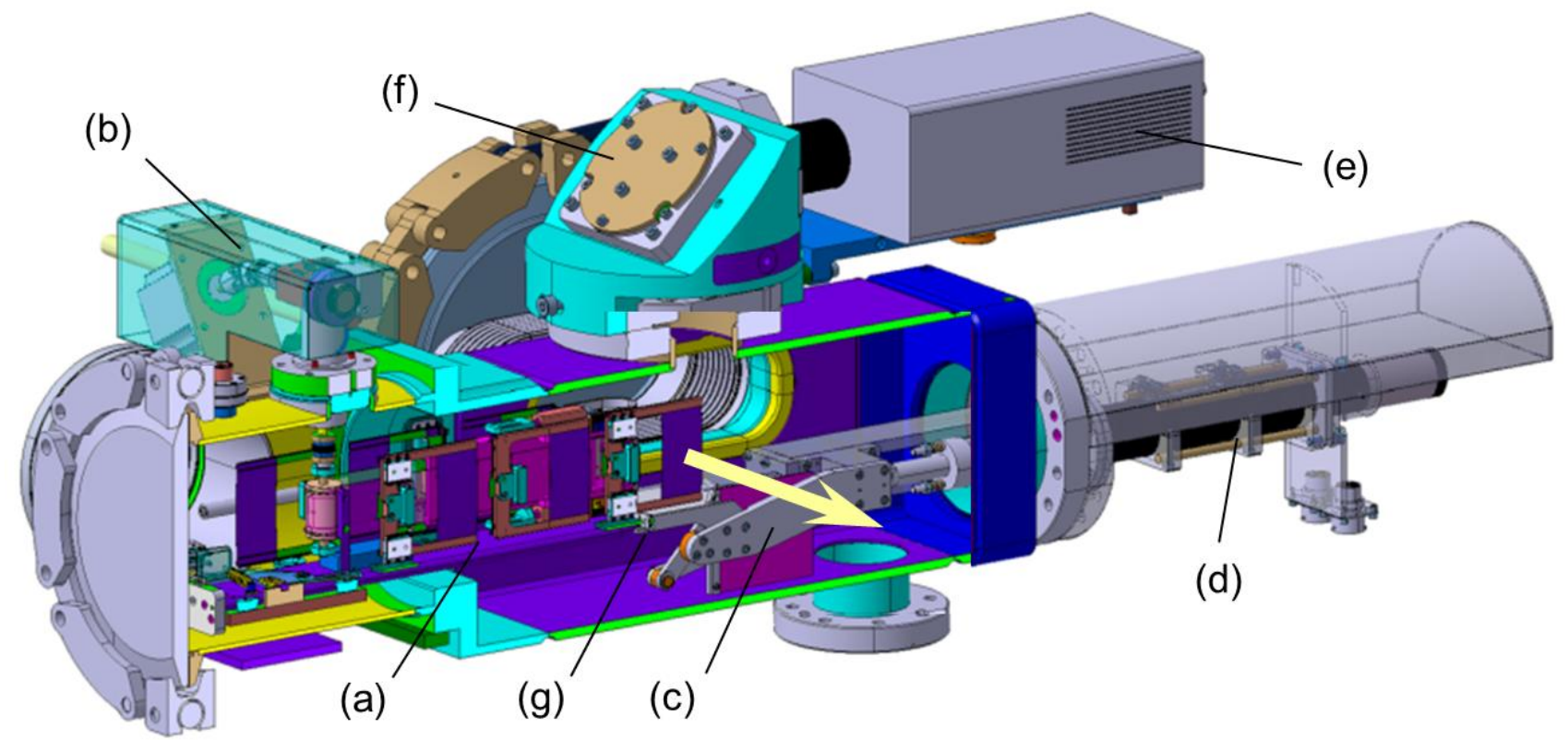

Fig. 3 Front view (right) and side view (left) of the stripping foil holder attached to the rotating belt with foil dimensions for the PSB injection. Nominal width of the holder is $71 \mathrm{~mm}$, but the unit allows for holders with a maximum dimension (a) up to $76 \mathrm{~mm}$. The foil has dimensions $21 \mathrm{~mm}$ x $58 \mathrm{~mm}$.

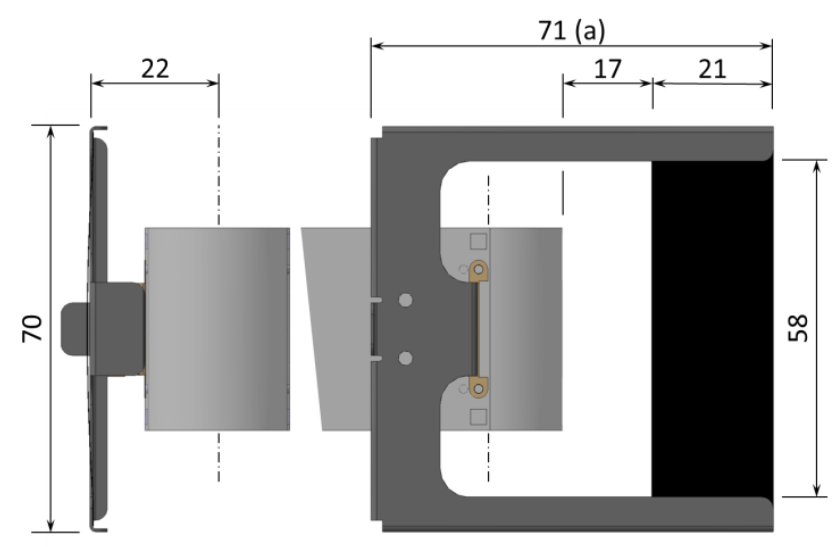


Fig. 4 Linac4 layout from PI-Mode Structure (PIMS) up to the main dump.

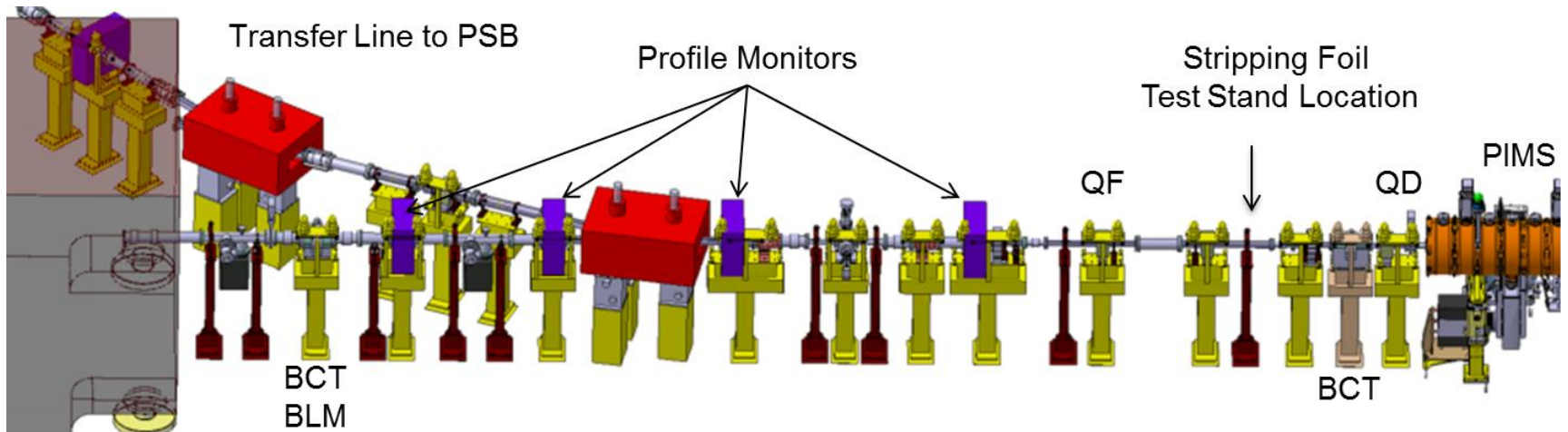




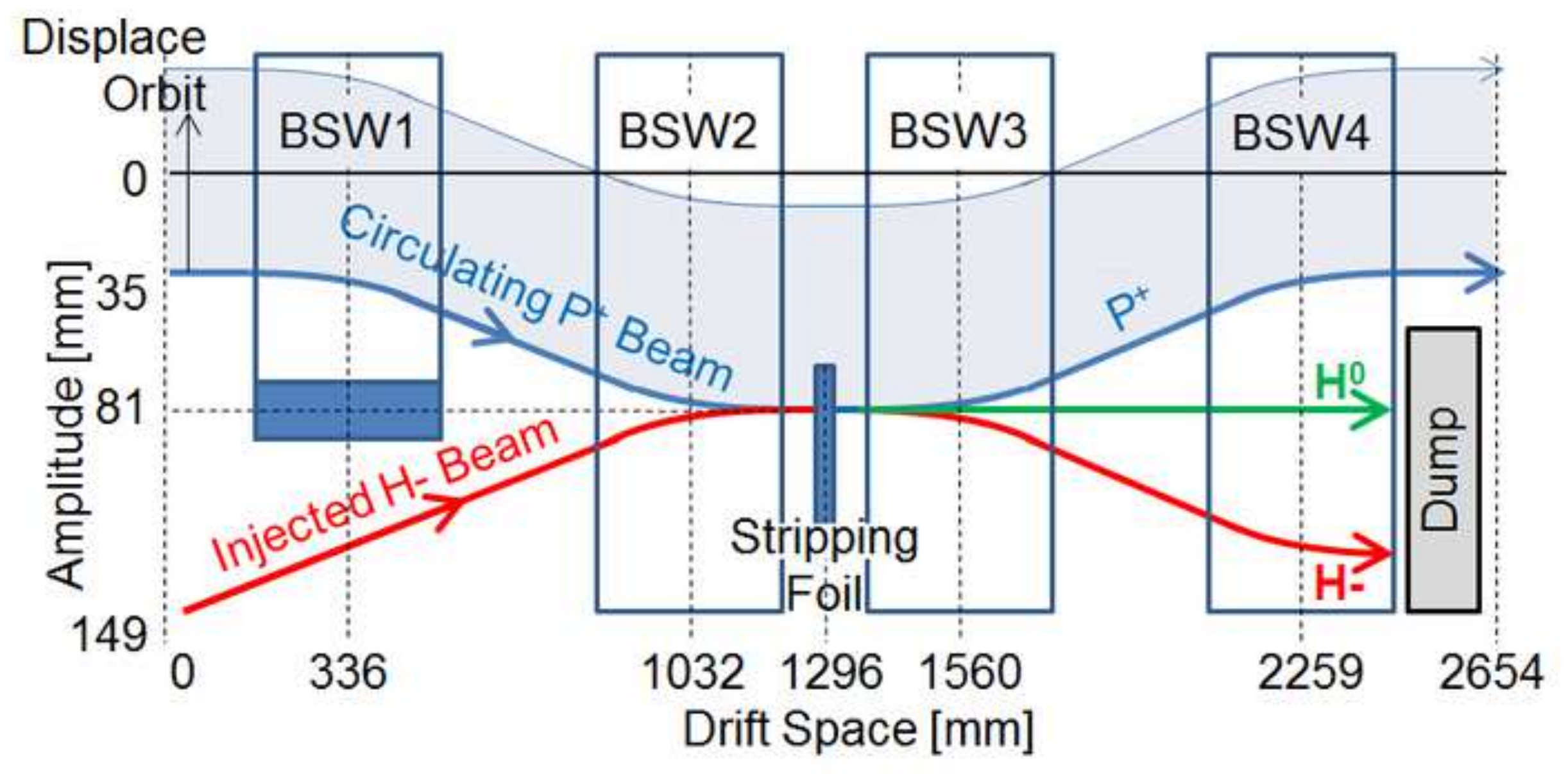




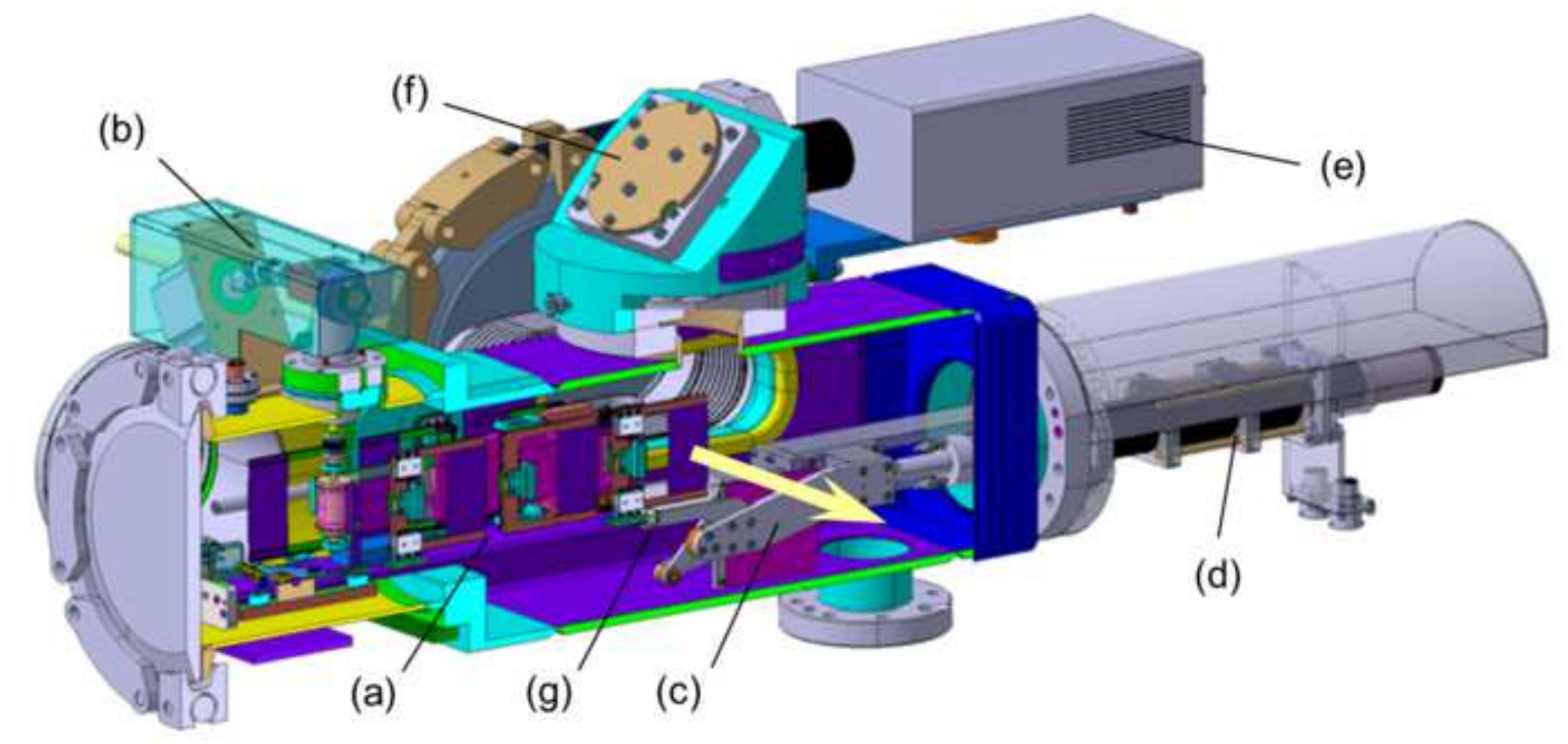




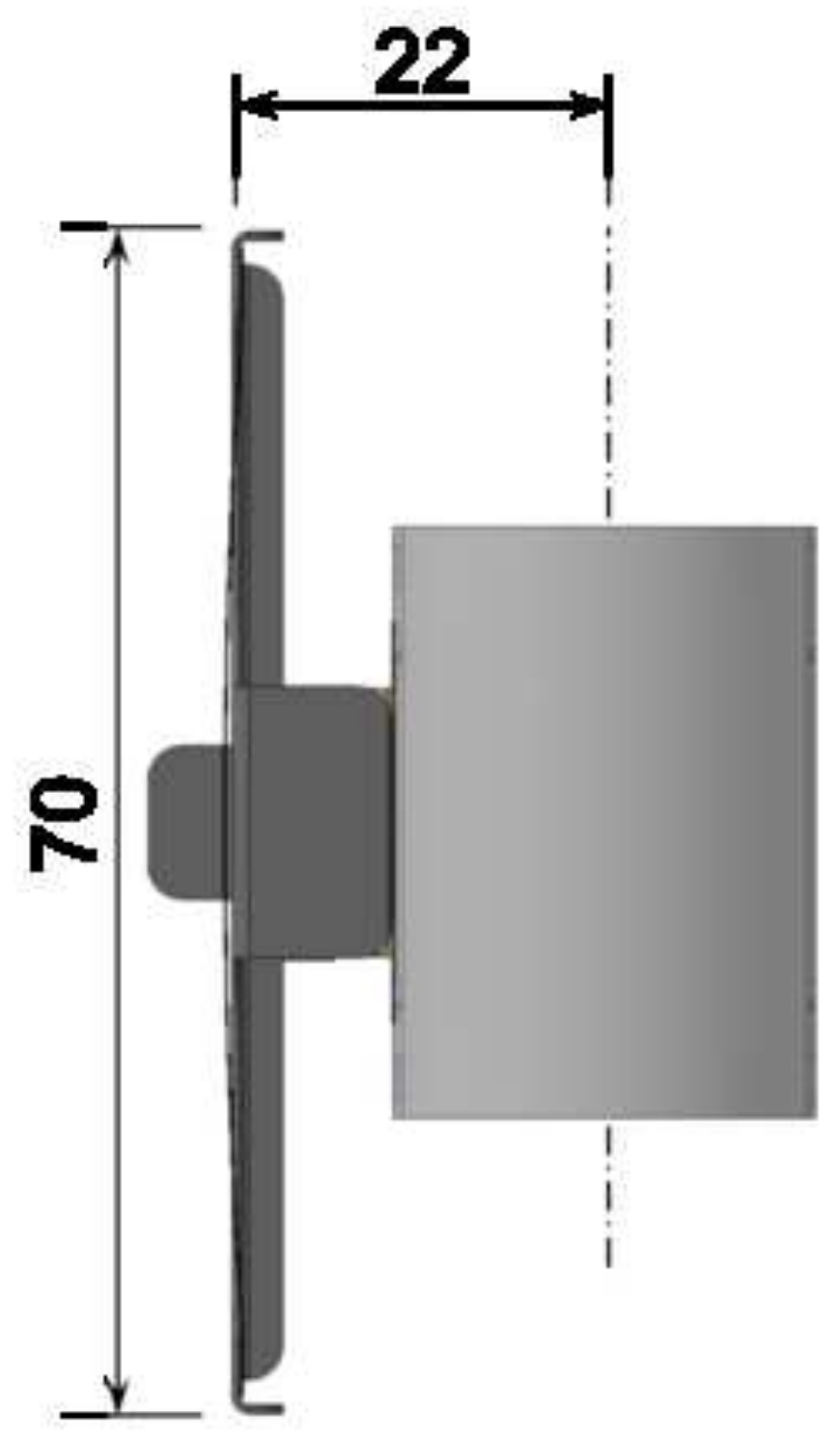

71 (a)
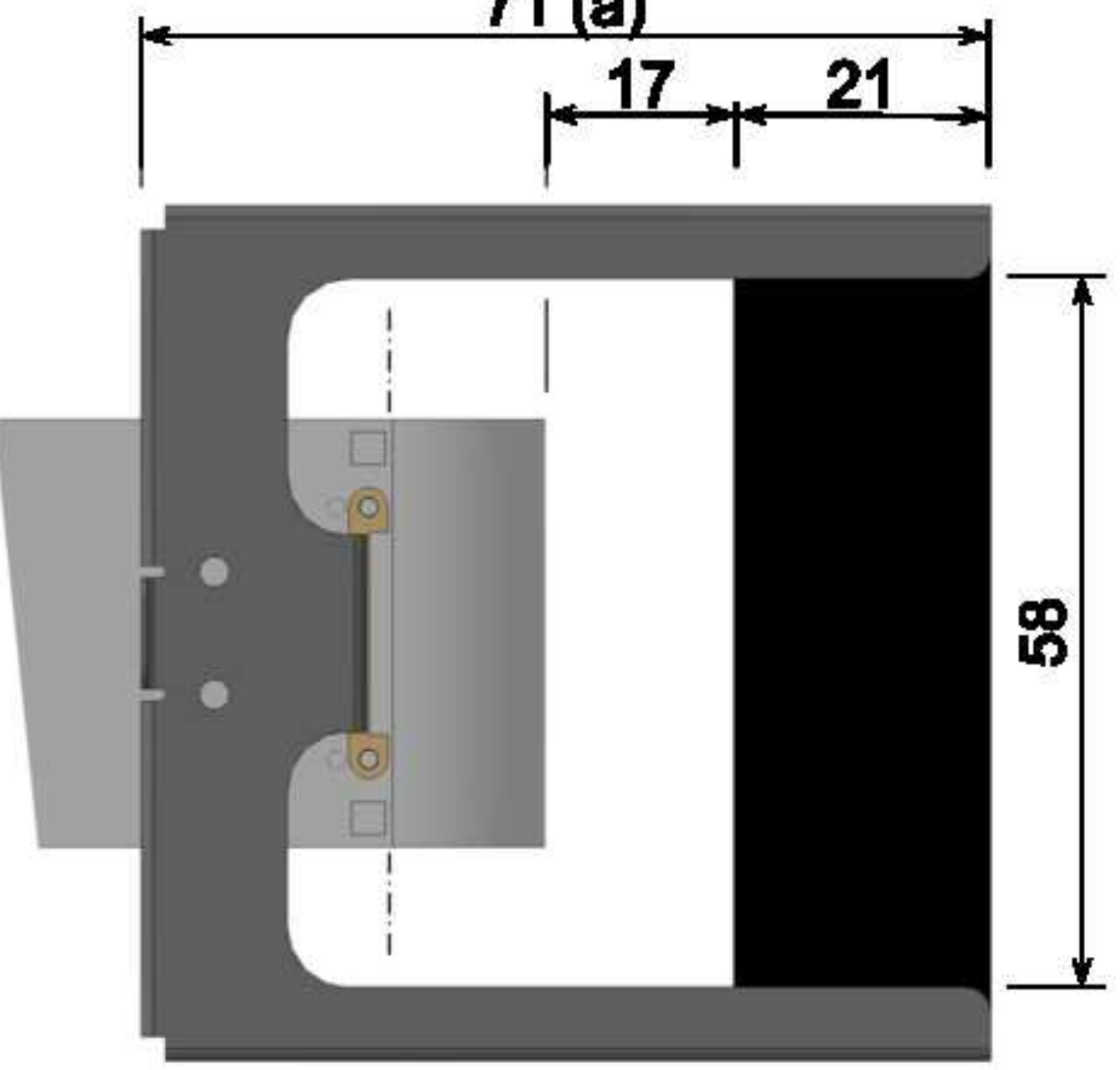


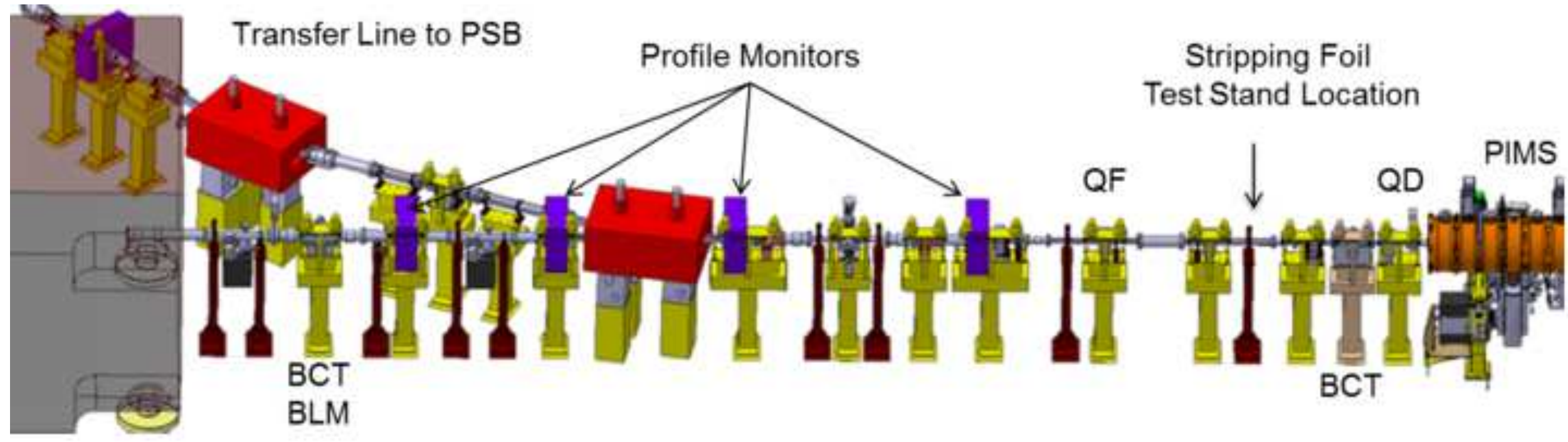




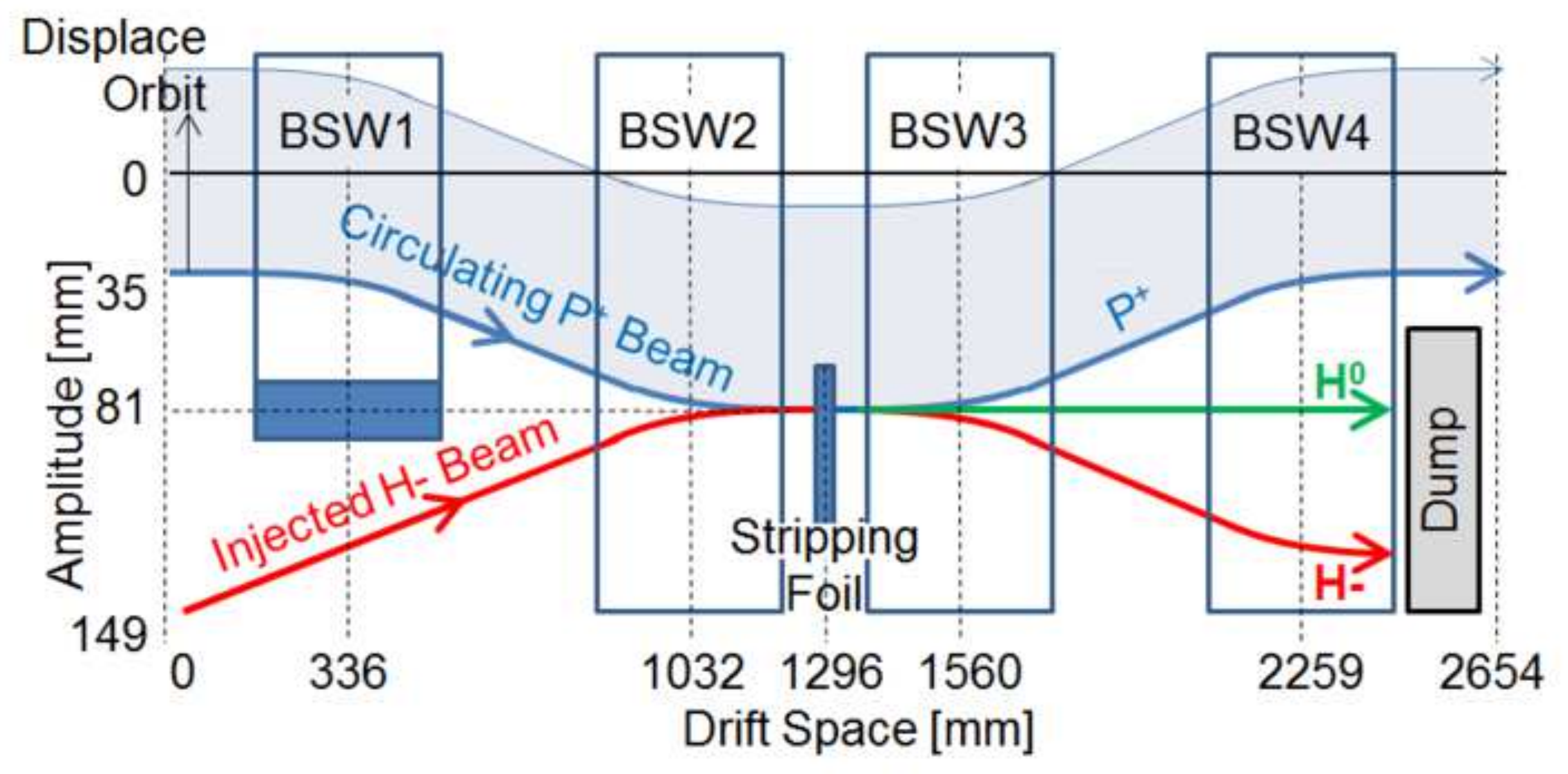




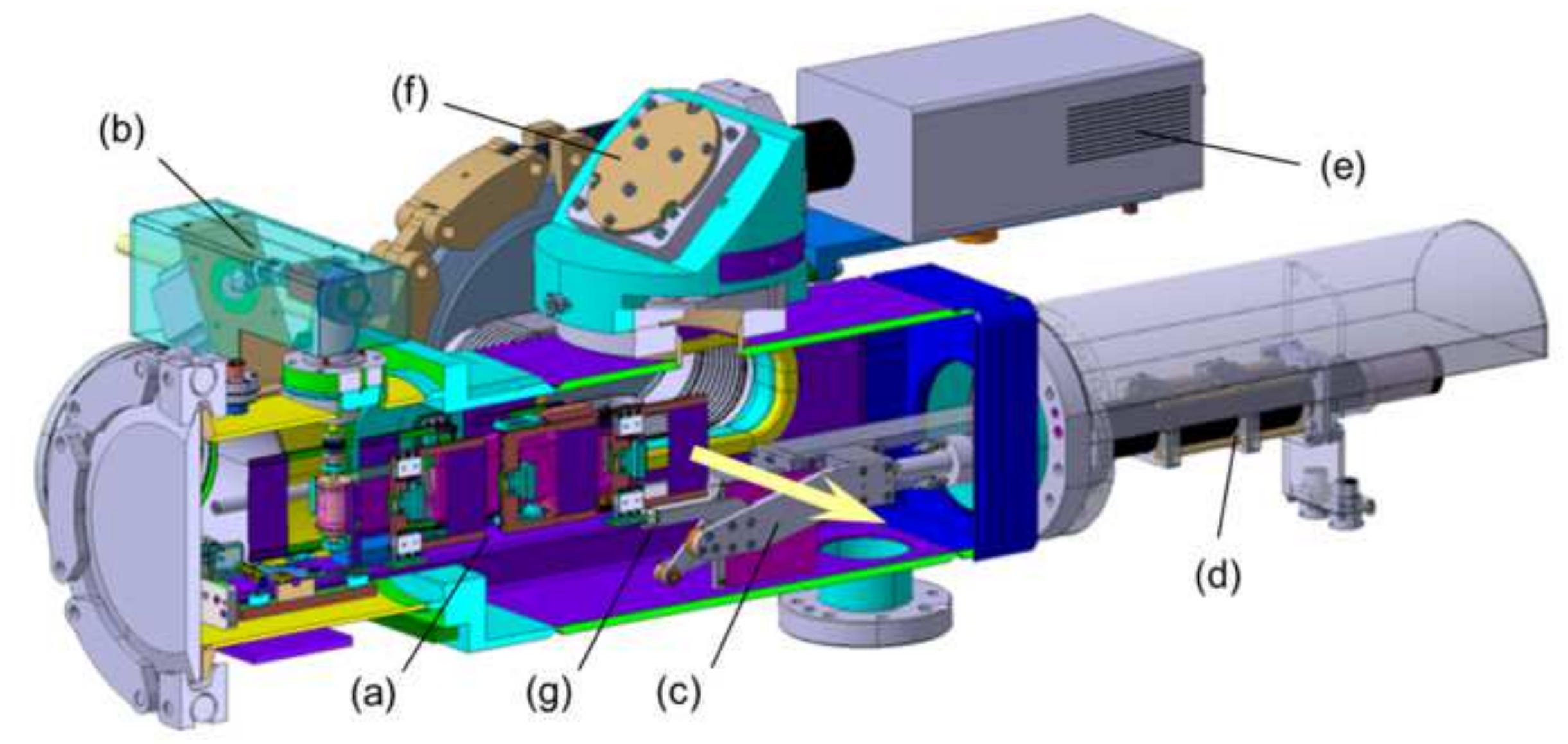




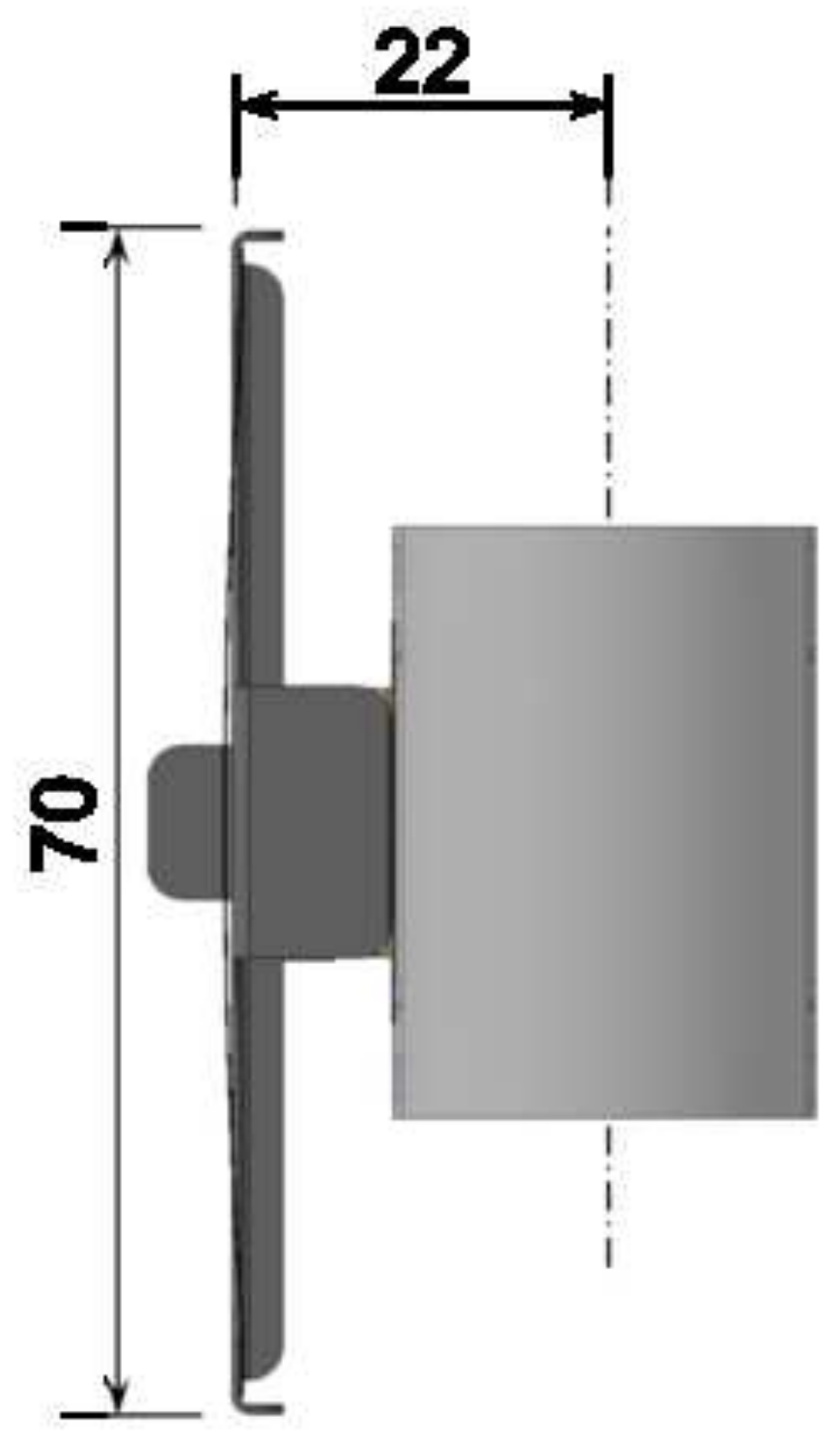

71 (a)
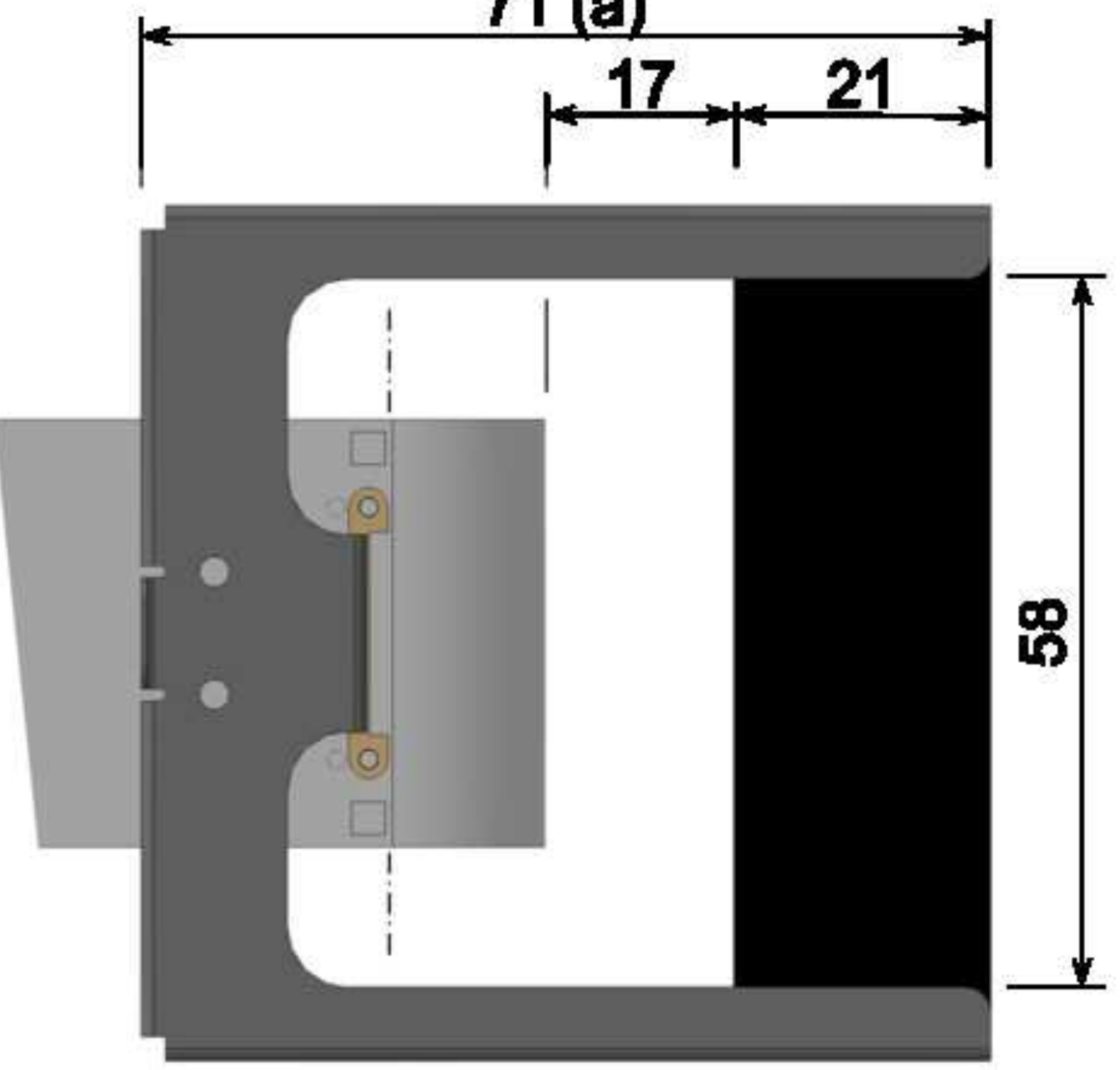


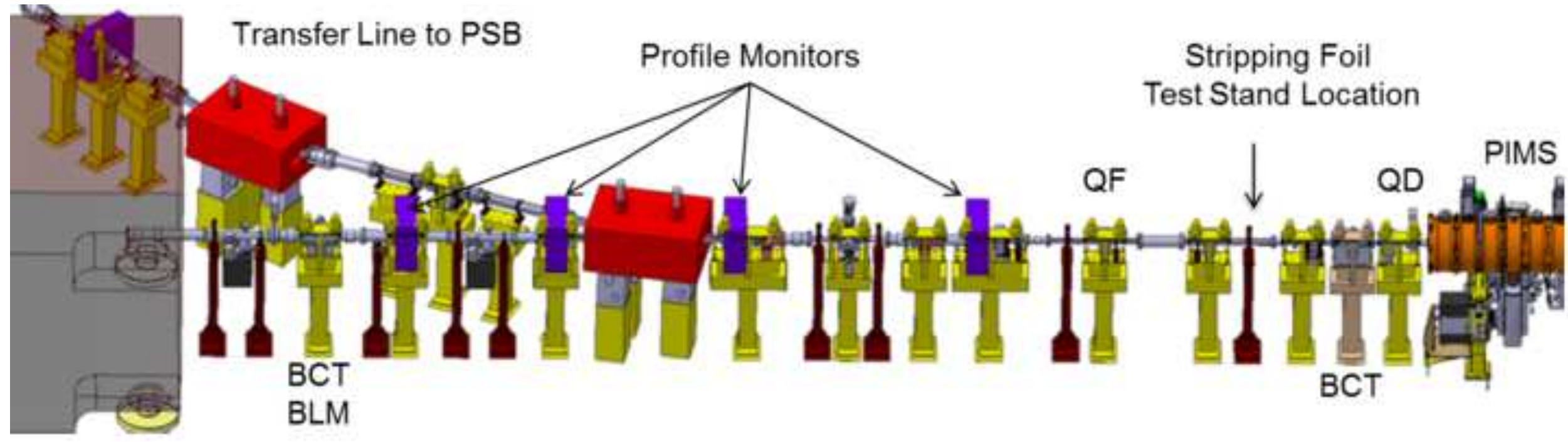

